\title{
Proximally Based Sural Artery Flap
}

\author{
ABDELLATIF ARAFA, M.D.* and GAMAL YOUSSEF, M.D.** \\ The Department of Plastic and Reconstructive Surgery, Shebin El-Kom Teaching Hospial* and Sohag University Hospital**
}

\begin{abstract}
Background: There have been few reports regarding the proximally based sural artery flap, which is useful for reconstruction of soft tissue defects around the knee and on the proximal third and middle third of the leg especially in the medial aspect of these sites.
\end{abstract}

Introduction: The proximally based sural fasciocutaneous flap is an ideal alternative for reconstruction of soft tissue defects around the knee and on the proximal half of the leg. Its advantages include a thin sensate flap, good aesthetic outcomes, and reduced donor site morbidity. However, there have been limited reports regarding its clinical application.

Objectives: The aim of this article is to review the use of proximally based sural flap for reconstruction of the knee region and our experience in its application in traumatic cases and in contracture release.

Methods: A total number of fifteen cases of proximally based sural artery flap were done in Shebin El-Kom Teaching Hospital and Sohag University Hospital from March 2013 to March 2016 with age ranges from ten to forty years with mean age was 26.9 years. Nine cases were postburn contracture and six cases was traumatic skin loss. Follow-up was done for at least 6 months.

Results: All flaps were survived with good functional results and acceptable cosmetic appearance. Donor site is covered by split thickness skin graft.

Conclusion: This proximally based sural fasciocutaneous flap was reliable and efficient to reconstruct soft-tissue defects around the knee and on the proximal part of the leg with more versatility than other flaps used. The coverage for soft-tissue defects was accepted. This flap is relatively easy to learn and is an ideal reconstructive choice especially in the medial side of the knee and popliteal fossa defects.

Key Words: Proximally based sural artery flap - Fasciocutaneous flaps of the leg - Leg reconstruction - Knee reconstruction.

\section{INTRODUCTION}

Soft-tissue skin defects around the knee are not uncommon and often caused by burn, traffic accidents, squeeze injury, surgical trauma or tumor excision. Reconstruction of defects is considered as a challenging operation due to thin and pliable skin appearance and restoration of knee function. There are various available methods for reconstruction of defects around the knee, such as local muscle flap, perforator flap, cross-leg flap or free flap etc. However, the outcomes of these methods are always unsatisfactory, frequently compromising knee joint function and appearance. The proximally based sural artery flap from the posterior calf region is used for reconstruction of such defects because thin, reliable and sensate skin appearance can be provided [1]. In this paper we will discuss the use of this flap for reconstruction and coverage of defects and contractures in the knee region and upper third of the leg and compare the results with other modalities of treatment.

\section{Surgical Technique:}

Patients were positioned prone or lateral and a tourniquet was placed in the proximal thigh and pressurized without exsanguinations. Anatomically, the proximally based sural fasciocutaneous flap was designed. The flap consisted of an islet of skin and subcutaneous fat, the superficial and deep fascia, sural nerve, lesser saphenous vein, and the superficial sural artery. The flap circulation mainly depends on the median superficial sural artery, which mostly originated from the popliteal artery.

Initially, a line is drawn on the posterior calf to indicate the course of the sural nerve and adjacent lesser saphenous vein, usually extending from the midpoint of the lateral malleolar tip and Achilles's tendon to the midpoint of the popliteal skin crease. The donor site is centered on this line, which also roughly marked the course of the pedicle. The pivot point of the pedicle is usually set on the line $1.5 \mathrm{~cm}$ to $2 \mathrm{~cm}$ distal to the popliteal skin crease. A skin islet is drawn. After measurement of the size and shape of the recipient site, the pivot point and pedicle length were determined and the donor site was designed centered on the line on the posterior 
calf indicating the course of the lesser saphenous vein and sural nerve.

Thereafter, the entire flap was dissected and elevated from distal to proximal. Initially, the skin and subcutaneous fascia were dissected distally to incorporate the deep fascia, the ligated lesser saphenous vein, and the sural nerve together. The lesser saphenous vein is always superficial, but the sural nerve penetrates the deep fascia at the midpoint of the lower leg and then follows a course between the 2 heads of the gastrocnemius muscle. Finally, the entire flap was elevated between the deep fascia and the aponeurosis of Achilles's tendon or gastrocnemius muscular fascia on the posterior calf until reaching the pivot point.

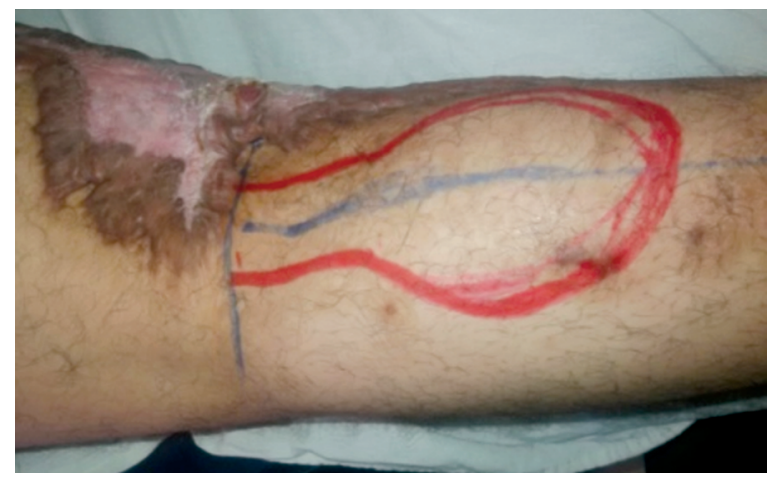

Case (1): Preoperative and design.

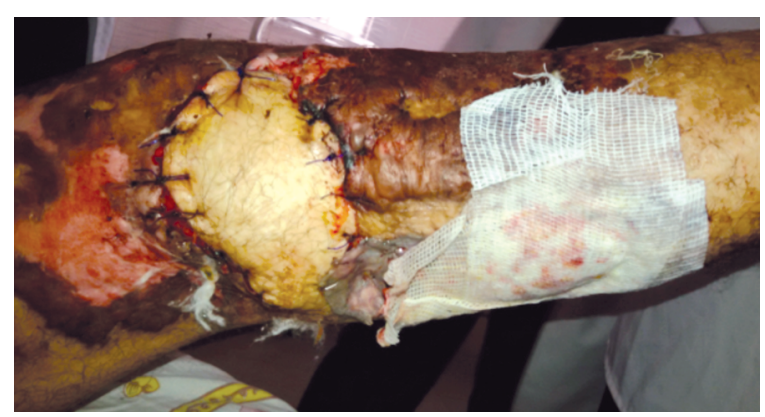

Case (1): Early postoperative.

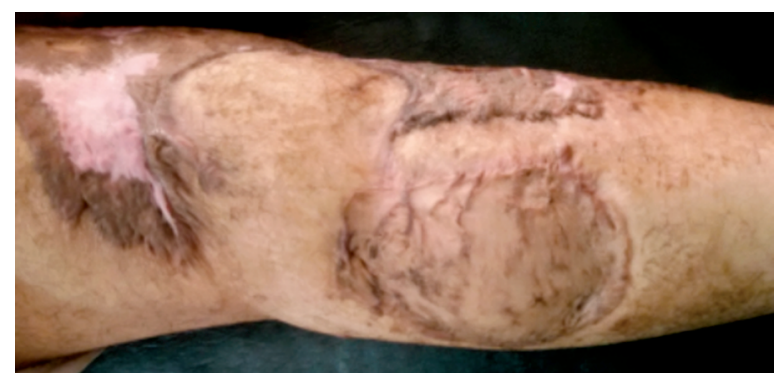

Case (1): Late postoperative.

\section{MATERIAL AND METHODS}

A total number of fifteen cases of proximally based sural artery flap were done in Shebin ElKom Teaching Hospital and Sohag University Hospital from March 2013 to March 2016 with age ranges from ten to forty years with mean age was 26.9 years. Nine cases were postburn contracture and six cases was traumatic skin loss in the medial aspect of the knee joint. Four cases were female and eleven cases were male. Donor site was covered by split thickness skin graft. Follow for at least 6 months.

\section{RESULTS}

Results are shown in Cases (1-5).

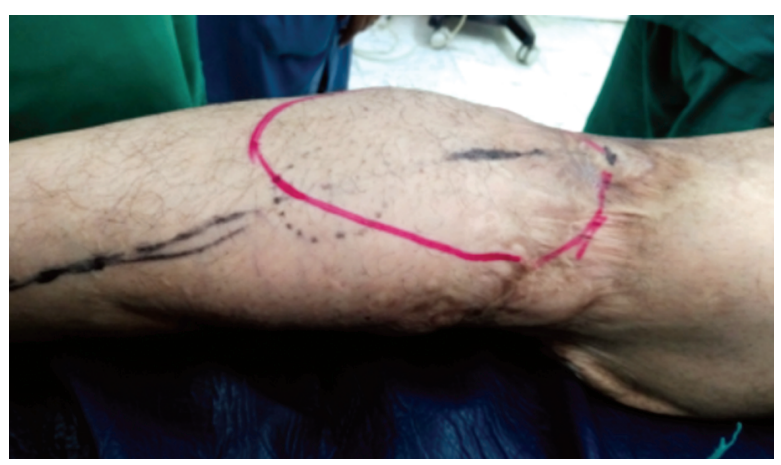

Case (2): Preoperative and design.

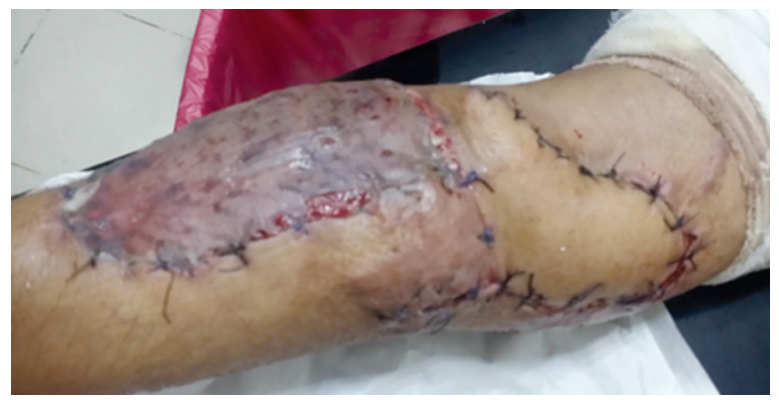

Case (2): Early postoperative.

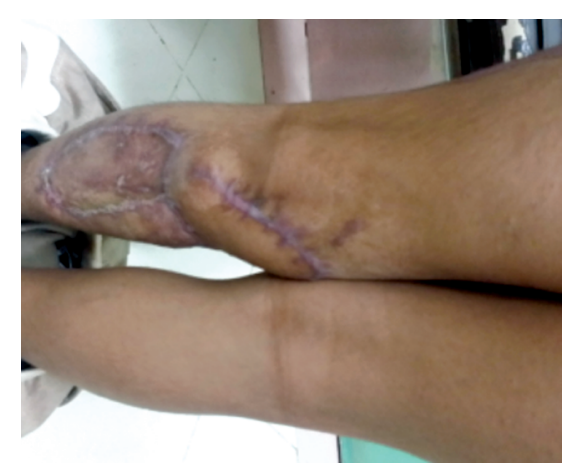

Case (2): Late postoperative. 


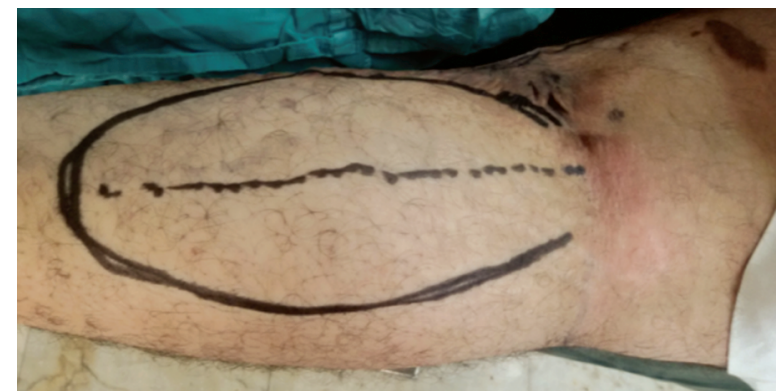

Case (3): Preoperative and design.

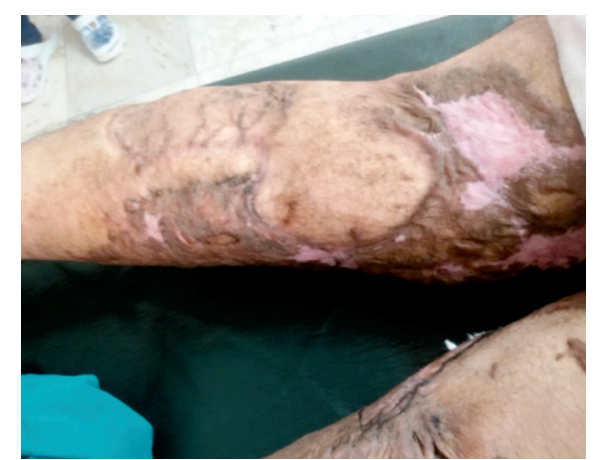

Case (3): Late postoperative.

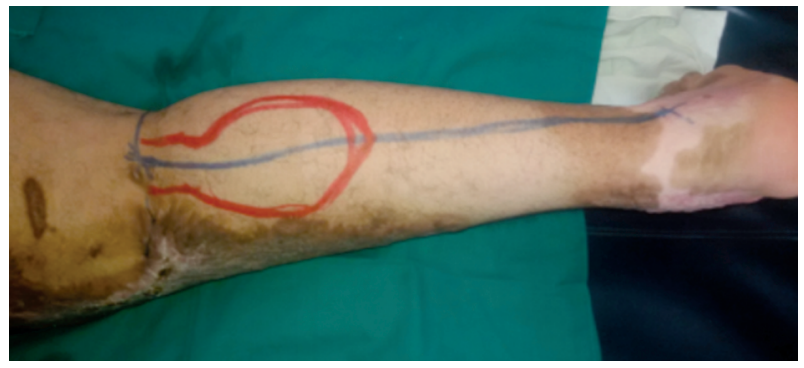

Case (4): Preoperative and design.

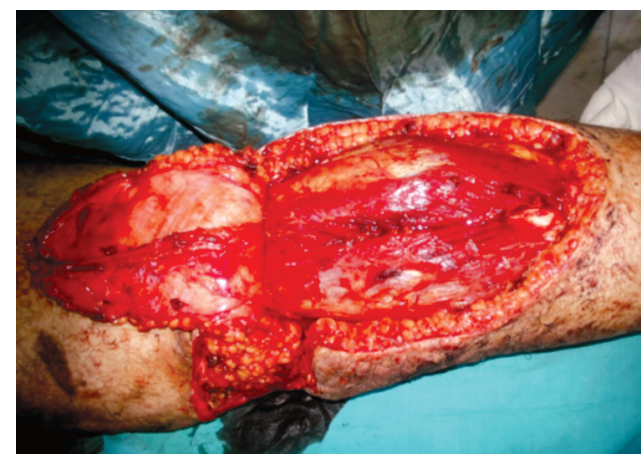

Case (4): Intreoperative.

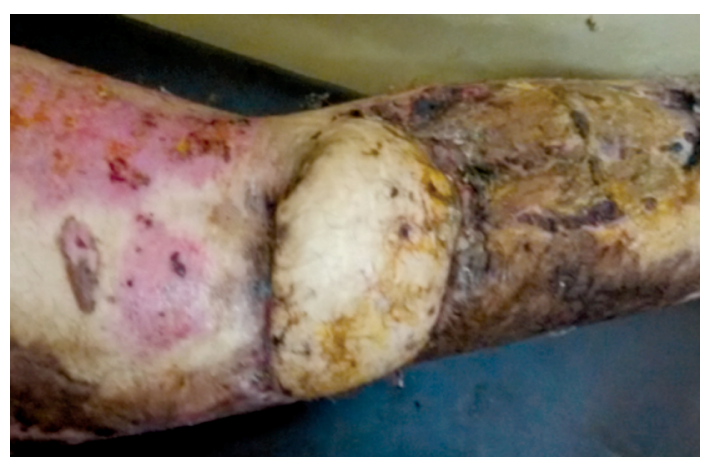

Case (4): Postoperative.

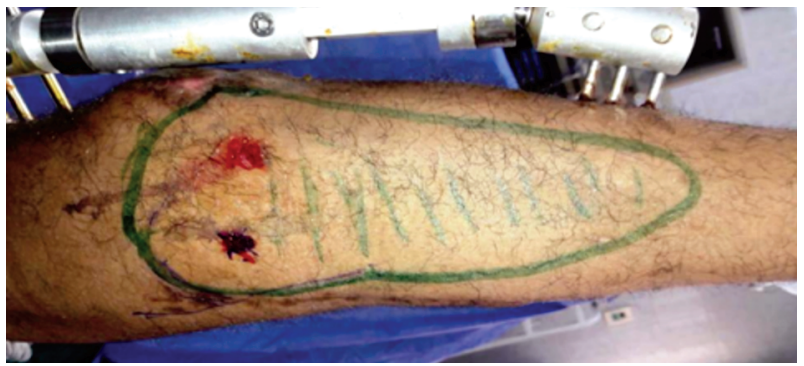

Case (5): Postoperative

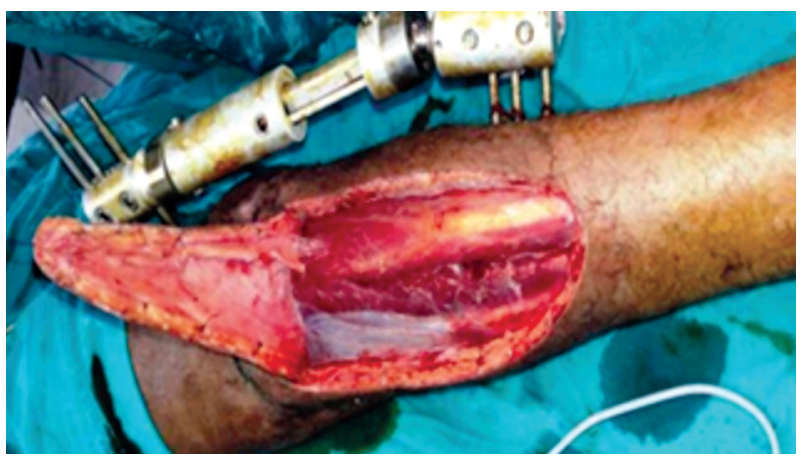

Case (5): Preoperative.

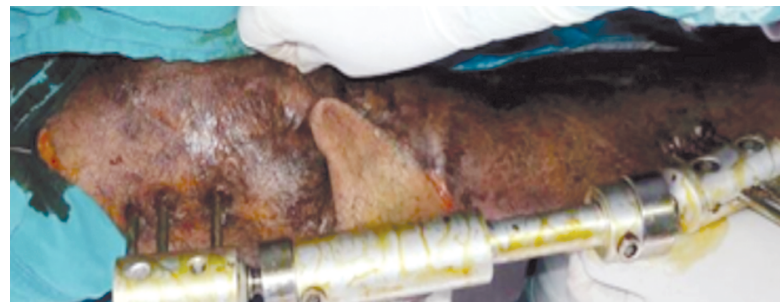

Case (5): Intraoparative.

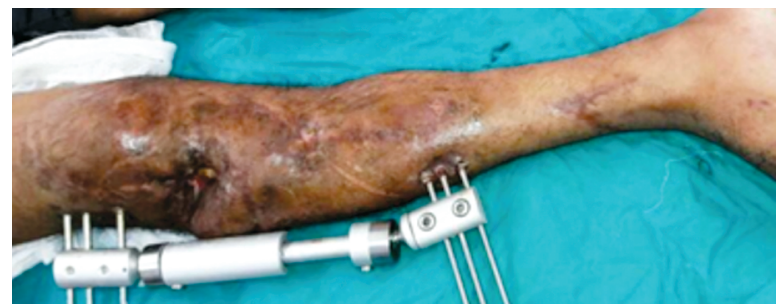

Case (5): Larly postoperative.

\section{DISCUSSION}

Soft-tissue defects around the knee and on the proximal lower leg are common due to trauma and postoncologic excision [4]. There are various options available for reconstruction of such defects, usually including local muscle flap, fasciocutaneous flap, free flap, perforator flap and cross-leg flap $[\mathbf{5 , 6 ]}$. Generally, a local muscle flap yields a bulky appearance and muscular function is damaged; a free flap requires excellent microsurgical technique, which limits its wide application. Cross-leg flap inevitably brings about severe discomfort and 2 
stage operation. While an island fasciocutaneous flap based on located perforator or fascial feeder vessels provides satisfactory coverage, as well as satisfactory cosmetic and functional outcomes but needs great dissection [7,8]. There have been limited clinical reports regarding proximally based sural fasciocutaneous flaps for such reconstructions $[4,9,10]$.

The knee area and upper third of the lower leg have an abundance of vessels and muscles. Thus, it appears possible that soft tissue defects in these sites may be treatable with a variety of reconstructive methods, but the outcomes of these methods may be unsatisfactory for several reasons. A local flap with muscles might yield unsatisfactory cosmetic and functional results, and both the perforator flap and free flap procedures are associated with technical difficulties [11,12]. The skin has less redundancy and a poor arterial supply below the proximal third of the lower leg, and superficial venous return in this area is frequently rendered ineffective. Hence, soft tissue defects that occur in this region are difficult to cover [13]. Modified neurocutaneous flap procedure developed by Masquelet et al., [14], several articles have described the effectiveness and usefulness of a distally based superficial sural artery flap $[\mathbf{1 5}, \mathbf{1 6}, \mathbf{1 7}]$. However, there have been few published clinical reports regarding proximally based sural artery flaps [18]. We evaluated the outcome of the proximally based sural artery flap for the reconstruction of soft tissue defects around the knee and on the proximal third and middle third of the lower leg.

Regarding the proximally based sural artery flap, a report [19], but no details of the procedure or outcome were described. The proximally based sural artery flap is a good choice for reconstruction of such defects. There is no morbidity of the donor site and minimal damage to the muscles, and the technique can provide excellent cosmetic results with a thin and sensate flap. The method also provides stretchable and sensate skin with a gliding undersurface, which does not restrict the excursion of the extensor apparatus. There is no need for microsurgical techniques, and an excellent survival rate can be expected provided there is constant blood supply. These flaps can cover not only the knee joint region and the proximal third of the lower leg, but also the middle third of the lower leg with sufficient pedicle length. The disadvantages of this flap include sensory disability in the dorsolateral aspect of foot, and scarring of the donor site can produce inferior cosmetic results [18].

\section{Conclusion:}

This proximally based sural fasciocutaneous island flap was reliable and efficient to reconstruct soft-tissue defects around the knee and on the proximal lower leg with more versatility than other flap techniques the authors has used for coverage of soft-tissue defects such as those described in this study. This flap is relatively easy to learn and is an ideal alternative.

\section{REFERENCES}

1- Chengliang Deng, Zairong Wei, Bo Wang, Wenhu Jin, Wenduo Zhang, Xiujun Tang, Bihua Wu, Guangfeng Sun and Dali Wang: The proximally based lateral superficial sural artery flap: A convenient and optimal technique for the reconstruction of soft-tissue defects around the knee Int. J. Clin. Exp. Med., 9 (8): 15167-15176, 2016.

2- Stephen J. Mathes and Foad Nahai.: Reconstructive Surgery Principles, Anatomy \& Tèchnique Sural Artery Flap. P. 1498, Churchill. Livingstone. Inc., 1997.

3- Haitao Pan, Qixin Zheng and Shuhua Yang.:Utility of Proximally Based Sural Fasciocutaneous Flap for Knee and Proximal Lower Leg Defects, Wounds, 26 (5): 132$138,2014$.

4- Suri M.P., Friji M.T., Ahmad Q.G. and Yadav P.S.: Utility of proximally based sural artery flap for lower thigh and knee defects. Ann. Plast. Surg., 64 (4): 462-465, 2010.

5- Zheng H.P., Lin J., Zhuang Y.H. and Zhang F.H.: Convenient coverage of soft-tissue defects around the knee by the pedicled vastus medialis perforator flap. J. Plast. Reconstr. Aesthet. Surg., 65 (9): 1151-1157, 2012.

6- Hong J.P. and Koshima I.: Using perforators as recipient vessels (supermicrosurgery) for free flap reconstruction of the knee region. Ann. Plast. Surg., 64 (3): 291-293, 2010.

7- Leclère F.M., Eggli S. and Mathys L.: Vögelin E. Anatomic study of the superficial sural artery and its implication in the neurocutaneous vascularized sural nerve free flap. [Epub ahead of print March 29]. Clin. Anat. doi: 10.1002/ca.22054, 2012.

8- Zhang Y.X., Zhang Y.G., Yang J., Wang D.R. and Qian Y.L.: Anatomy and clinical application of posterior calf fasciocutaneous flap [in Chinese]. Zhonghua Zheng Xing Wai Ke. Za. Zhi., 24 (3): 192-195, 2008.

9- Cheon S.J., Kim I.B., Park W.R. and Kim H.T.: The proximally-based sural artery flap for coverage of soft tissue defects around the knee and on the proximal third and middle third of the lower leg: 10 patients followed for 1-2.5 years. Acta. Orthop., 79 (3): 370-375, 2008.

10-Dai J., Chai Y., Wang C. and Wen G.: Proximal-based saphenous neurocutaneous flaps: A novel tool for reconstructive surgery in the proximal lower leg and knee. J. Reconstr. Microsurg., 29 (6): 373-378, 2013.

11-Rajacic N., Gang R.K., Darweesh M., Abdul F.N. and Kojic S.: Reconstruction of soft tissue defects around the knee with the use of the lateral sural fasciocutaneous artery island flap. Eur. J. Plast. Surg., 22 (1): 12-6, 1999. 
12- Shim J.S. and Kim H.H.: A novel reconstruction technique for the knee and upper one third of lower leg. J. Plast. Reconstr. Aesthet. Surg., 59 (9): 929-34, 2006.

13-Hasegawa M., Torii S., Katoh H. and Esaki S.: The distally based superficial sural artery flap. Plast. Reconstr. Surg., 93 (5): 1012-20, 1994.

14-Masquelet A.C, Romana M.C. and Wolf G.: Skin island flaps supplied by the vascular axis of the sensitive superficial nerves: Anatomic study and clinical experience in the leg. Plast. Reconstr. Surg., 89 (6): 1115-21, 1992.

15- Rajacic N., Darweesh M., Jayakrishnan K., Gang R.K. and Jojic S.: The distally based superficial sural flap for reconstruction of the lower leg and foot. Br. J. Plast. Surg., 49 (6): 383-9, 1996.

16- Huisinga R.L., Houpt P. and Dijkstra R.: Storm van
Leeuwen J B. The distally based sural artery flap. Ann. Plast. Surg., 41 (1): 58-65, 1998.

17- Le Fourn B., Caye N. and Pannier M.: Distally based sural fasciomuscular flap: Anatomic study and application for filling leg or foot defects. Plast. Reconstr. Surg., 107 (1): 67-72, 2001.

18- Sang-Jin Cheon, Bo Kim, Won-Ro, and Hui-Taek Kim: The proximally-based sural artery flap for coverage of soft tissue defects around the knee and on the proximal third and middle third of the lower leg 10 patients followed for 1-2.5 years. Acta. Orthopaedica, 79 (3): 370375,2008

19- Meyer C., Hartmann B., Horas U., Kilian O., Heiss C. and Schnettler R.: Reconstruction of the lower leg with the sural artery flap. Langenbecks Arch. Surg., 387 (78): 320-5, 2002. 